\title{
ANALISIS SPASIAL PERBANDINGAN JUMLAH ANAK USIA SD DAN RUANG KELAS KECAMATAN BULU KABUPATEN SUKOHARJO
}

\author{
MS Khabibur Rahman ${ }^{1)}$, Bambang Partono ${ }^{2)}$ \\ ${ }^{1,2}$ Universitas Veteran Bangun Nusantara Sukoharjo \\ ${ }^{1,2} \mathrm{Jl}$. Letjend. S. Humardani No.1 Sukoharjo \\ E-mail: khabib_ynwa@yahoo.co.id ${ }^{1)}$, bambang.partono@gmail.com ${ }^{2)}$
}

\begin{abstract}
Abstrak - Tujuan penelitian ini adalah : (1) mengetahui persebaran sekolah dasar di Kecamatan Bulu serta, dan (2) mengetahui perbandingan jumlah anak usia sekolah dasar dengan jumlah ruang kelas di Kecamatan Bulu Kabupaten Sukoharjo pada tahun 2015. Dalam usaha mengetahui persebaran dan kecukupan ruang sekolah dan ruang kelas yang ada di Kecamatan Bulu, digunakan metode penelitian pemetaan serta penggunaan rumus APM (Angka Partisipasi Murni) yang telah dimodifikasi berdasarkan Permendiknas No. 15 Tahun 2010. Data lokasi sekolah diperoleh dengan cara Ploting menggunakan GPS, sedangkan jumlah anak usia sekolah dasar diperoleh dengan pengambilan data ke masing-masing kelurahan. Teknik analisis data dilakukan dengan cara mengolah data hasil ploting dan peletakannya pada peta dasar menggunakan Sistem Informasi Geografis (SIG) sehingga menghasilkan peta persebaran SD di kecamatan Bulu, serta hasil perhitungan perbandingan jumlah anak usia sekolah dasar dengan jumlah ruang kelas. Hasil penelitian menunjukkan sekolah dasar di Desa di Kecamatan Bulu berjumlah 24 sekolah, yang paling banyak di Desa Bulu dengan 4 sekolah terdiri dari 3 sekolah negri dan 1 sekolah swasta. Jumlah ruang kelas sekolah dasar di Kecamatan Bulu mengalami kelebihan berdasarkan perhitungan perbandingan anak usia sekolah dasar dengan jumlah ruang kelas yang tersedia
\end{abstract}

Kata Kunci: Pemetaan, Ruang Kelas

\begin{abstract}
These research aims to: (1) determine the distribution of elementary schools in the sub-district of Bulu, and (2) to know the comparative number of children in primary school age with the number of classrooms in Bulu sub-district, District of Sukoharjo in 2015. This research used Mapping Research Methods and modified APM formula (enrollment rates) based on Permendiknas No. 15 of 2010 to know the distribution and adequacy of school space and classrooms in Bulu sub-district.The data of school location was obtained by plotting using GPS while the number of primary school age children was coming from field survey to each village. The analysis data technique was done by processing the result of plotting data and put it on the base map using Geography Information System (GIS) in order to produce the map of elementary school distribution in Bulu sub-district, in tandem with the comparison result between the number of primary age children and the number of classrooms. The findings showed that the number of elementary schools in Bulu sub-district was 24 in which the majority number was in Bulu village with three public schools and one private school. The number of elementary school's classes in Bulu sub-district experienced an excess based on the ratio of the number of students with the available classrooms.
\end{abstract}

Keywords: Mapping, Class Room 


\section{PENDAHULUAN}

UU No. 20 Tahun 2003 tentang Sistem Pendidikan Nasional menjelaskan arti pendidika adalah usaha sadar dan terencana untuk mewujudkan suasana belajar dan proses pembelajaran agar peserta didik secara aktif mengembangkan potensi dirinya untuk memiliki kekuatan spiritual keagamaan, pengendalian diri, kepribadian, kecerdasan, akhlak mulia, serta ketrampilan yang diperlukan di masyarakat. Dalam mewujudkan suasana belajar yang nyaman, ditemui banyak kendala dilapangan yang menghambat usaha tersebut, antara lain terkait sarana dan prasaran pendidikan itu sendiri.

Salah satu masalah yang menjadi sorotan adalah jumlah sekolah dan ruang kelas yang ada di suatu daerah, terkadang tidak seimbang dengan jumlah siswa. Jika jumlah siswa terlalu banyak sedangkan ruang kelas sedikit, maka akan banyak siswa yang tidak tertampung, sebaliknya jika terlalu banyak ruang kelas namun jumlah siswanya sedikit, akan banyak ruang kelas yang tidak terisi oleh siswa.

Salah satu contoh peristiwa yang terjadi di daerah adalah sekolah yang kekurangan siswa seperti dimuat dalam situs berikut : "Sejumlah sekolah swasta di Kota Serang terancam tutup karena jumlah siswanya terus menurun akibat kalah saing dengan sekolah negeri. Hal ini dilihat dari jumlah siswa mereka yang semakin sedikit. Bahkan ada yang membuka satu kelas dengan jumlah tidak sampai 20 orang, salah satunya adalah SMA Mardi Yuana yang lokasinya tidak jauh dari Alun-alun Kota serang." http://www.citizenjurnalism.com/worldnews/indonesia/sekolah-swasta-di-kota-serang- terancam-tutup/. Melihat fenomena diatas, maka perlu segera dilakukan kajian mengenai persebaran sekolah dasar beserta kecukupan ruang kelas untuk siswa. Dengan bantuan teknologi, akan lebih mudah melakukan analisis persebaran SD serta melakukan pemetaan kecukupan ruang kelas dengan satuan analisis adalah desa yang ada di Kecamatan Bulu Kabupaten Sukoharjo.

Bintarto dan Hadisumarno

(1991:12) mendefinisikan analisis keruangan adalah adalah mempelajari perbedaan lokasi mengenai sifatsifat penting atau seri sifat penting. Titik berat dari analisis keruangan adalah distribusi dari ruang yang telah ada serta rancangan bagi penggunaan ruang yang akan digunakan. Adapun data dalam keruangan yang digunakan, berupa 3 jenis data yaitu data titik, data garis dan data luasan (area).

Kajian analisis keruangan dilakukan dengan pendekatan keruangan, yang merupakan suatu cara pandang atau kerangka analisis yang menekankan pada eksistensi ruang itu sendiri. Eksistensi ruang dalam perspektif geografi dapat dipandang dari struktur (spatial structure), pola (spatial pattern), dan proses (spatial processes). Yunus (2007:52-53) mendefinisikan pola sebagai kekhasan distribusi gejala tertentu di dalam ruang atau wilayah. Pola keruangan ditunjukkan dengan mengamati gejala berdasarkan kenampakan point features, line features, dan areal features.

Geografi yang mempunyai ciri utama atau kekhasan berupa peta, akan sangat membantu dalam usaha analisis keruangan. Peta tematik yang dibuat akan menggambarkan persebaran sekolah yang ada di Kecamatan Sukoharjo, serta 
kecukupan ruang kelas di Kecamatan Sukoharjo dengan satuan anlisis desa. Untuk membuat peta tematik akan menggunakan sebuah perangkat lunak untuk membuat peta yaitu Sistem Informasi Geografis (SIG). Dalam perkembangannya, analisis spasial sendiri dibedakan menjadi dua bentuk yaitu analisis spasial berbasis sistem informasi geografis sederhana (Simple GIS-based spatial analysis) dan analisis spasial yang berbasis sistem informasi geogafis lanjut (Advanced GIS-based spatial analysis). http://infomygis.blogspot.com.

Peta secara umum dapat diartikan sebagai gambaran roman muka bumi yang digambarkan pada bidang datar dan diperkecil menggunakan skala serta ditambah informasi-informasi guna kepentingan penafsiran peta. Dalam penggambarannya, peta digambarkan secara dua dimensi untuk mencerminkan fenomena grafikal yang dilakukan secara sistematis serta diperlukan kemampuan khusus untuk membuat dan membacanya. Menurut Villanueva (1978: 2) adapun fungsi peta misalnya sebagai berikut: 1 ). Memperlihatkan posisi atau lokasi relative 2). Memperlihatkan ukuran (dari petandapat diukur luas daerah dan jarak-jarak di atas permukaan bumi). 3). Memperlihatkan bentuk-bentuk obyek di permukaan bumi dengan skala tertentu. 4). Menghimpun dan menyeleksi (peta menghimpun data dari suatu daerah dan menyatakannya di atas permukaan dengan ukuran yang secukupnya).

Menurut Subagio (2003:3) Berdasarkan jenis data yang disajikan, peta dapat digolongkan menjadi dua kelompok, yaitu : 1). Peta Topografi adalah peta yang menggambarkan semua unsure topografi yang Nampak di permukaan bumi, baik unsure alam (seperti gunung, garis pantai, danau, hutan, dsb) maupun unsure buatan manusia (seperti jalan, pasar, permukiman, dsb) serta menggambarkan pula keadaan relief permukaan bumi. 2). Peta Tematik adalah peta yang hanya menyajikan data-data atau informasi dari suatu konsep / tema yang tertentu saja, baik itu berupa data kualitatif maupun data kuantitatif, dalam hubungannya dengan detail topografi yang spesifik, terutama yang sesuai dengan tema peta tersebut.

Seorang pembuat peta harus mampu mendesain peta dan merekayasa peta, mengkombinasikan berbagai jenis data menjadi symbol-simbol yang mudah dimengerti dan dipahami sehingga peta yang dihasilkan memiliki nilai yang tinggi baik dari segi kualitas peta atau isi peta serta dari segi seninya. Dengan peta yang baik maka akan lebih mudah bagi pembaca peta untuk memahami apa yang dimaksud didalam peta. Untuk membuat peta yang baik dalam arti memenuhi syarat kartografis dan dibuat secara sistematis, maka harus dilakukan secara runtut pula, dengan langkah sebagai berikut :

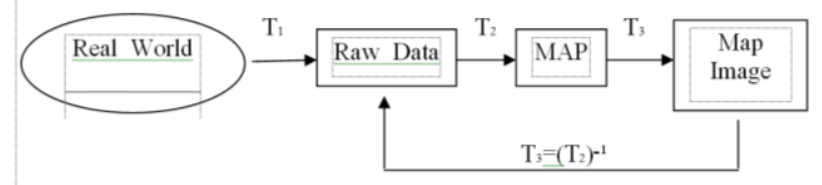

\section{Gambar 1. Proses Kartografi}

Keterangan:

Real World : Data Lapangan.

T1 : Pengumpulan Data.

Raw Data : Data mentah hasil pengumpulan data.

: Proses pengolahan data yang meliputi analisis, klasifikasi dan 
simbolisasi pada peta (transformasi).

Map : Peta yang dihasilkan.

T3 : Pembaca dan interpretasi peta dengan harapan pengguna peta dapat memahami dan memperoleh gambaran tentang data aslinya.

Map Image : Pengertian/kesan dari pengguna peta sehubungan dengan peta yang dibaca.

T3=(T2)- 1 : Berarti tahap pembacaan peta (T3) merupakan tahap yang tidak dapat dilepaskan atau erat kaitannya dengan tahap pemetaan (T2 ) semakin baik tahap pemetaan data akan lebih memudahkan pengguna peta dalam pembacaan petayang didukung oleh data mentah sebagai sumber datanya.

Peta sebagai alat komunikasi antara pembuat peta dan pembaca peta harus mempunyai tampilan dan isi yang sesuai namun tidak ruwet. Perlu dilakukan penataan desain peta yang meliputi informasi peta dan isi peta. Penataan isi peta dan informasi tepi harus dibuat secara harmonis, serasi dan seimbang. Dalam penempatan dan pengaturan informasi tepi ini perlu diperhatikan : 1). Bagian yang kosong dalam lembar peta. 2). Skala peta yang digunakan 3). Keseimbangan dalam meletakkan informasi tepi pada peta. Adapun desain tata letak peta dapat dilihat sebagai berikut :

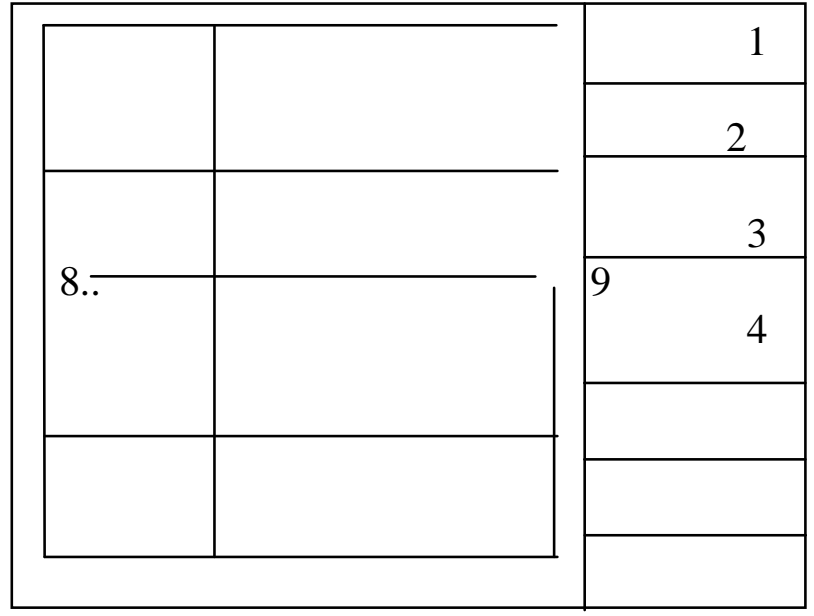

Gambar 2. Desain Tata Letak Peta

Keterangan :

1. Judul Peta

6. Sumber

2. Skala Peta

7. Pembuat Peta

3. Orientasi

8. Grid

4. Legenda

9. Garis Tepi

5. Insert

Undang-undang Sistem Pendidikan Nasional mendefinisikan pendidikan sebagai usaha sadar dan terencana untuk mewujudkan suasana belajar dan proses pembelajaran agar peserta didik secara aktif mengembangkan potensi dirinya untuk memiliki kekuatan spiritual keagamaan, pengendalian diri, kepribadian, kecerdasan, akhlak mulia, serta keterampilan yang diperlukan dirinya, masyarakat, bangsa dan negara. Dijelaskan pula bahwa jalur pendidikan yang dapat ditempuh ada tiga jenis yaitu pendidikan formal, nonformal dan informal. Untuk pendidikan formal merupakan pendidikan yang terstruktur dan berjenjang terdiri atas pendidikan dasar, pendidikan menegah dan pendidikan tinggi.

Pendidikan dasar merupakan landasan untuk dapat menempuh pendidikn menengah, dengan 
bentuk Sekolah Dasar (SD), Madrasah Ibtidaiyah (MI), Sekolah Menengah Pertama (SMP) dan Madrasah Tsanawiyah (MTS). Persebaran sekolah yang ada di suatu daerah haruslah merata dan berpusat pada satu lokasi saja, sehingga pemerataan pendidikan dapat tercapai. Jika keberadaan sekolah tidak merata dan hanya terjadi pada satu titik saja, maka akan terjadi kelebihan ruang kelas. Satu hal yang menjadi perhatian adalah jika ruang kelas di suatu daerah terlalu banyak, namun jumlah siswa sedikit maka akan banyak ruang kelas yang kosong, sebaliknya jika di daerah hanya sedikit ruang kelas dan jumlah siswanya banyak, maka akan terjadi overload daya tamping siswa. Penelitian kali ini dititik beratkan pada persebaran sekolah dasar dan angka kecukupan ruang kelas sekolah dasar yang ada di Kecamatan Bulu Kabupaten Sukoharjo Tahun 2014.

\section{METODE PENELITIAN}

Penelitian dilakukan di seluruh SD yang ada di daerah administrasi Kecamatan Bulu Kabupaten Sukoharjo. Metode penelitian yang digunakan dalam penelitian ini adalah penelitian deskriptif. Metode penelitian deskriptif (Sumadi, 2012:75) adalah penelitian yang bermaksud untuk membuat pencandraan (deskripsi) mengenai situasi - situasi atau kejadian kejadian. Untuk menggambarkan secara sistematis mengenai karakteristik populasi secara keruangan, dalam hal ini persebaran SD dan perbandingan anak usia sekolah dengan jumlah ruang kelas SD di Kecamatan Bulu digunakan metode penelitian deskriptif spasial.
Perolehan data di lapangan harus dilakukan dengan seksama, karena tidak semua data di lapangan dapat digunakan dalam penelitian. Data yang dikeluarkan oleh dinas yang berkompeten saja yang dianggap benar dan dapat digunakan dalam penelitian. Ada dua jenis data yang digunakan dalam penelitian ini, yaitu data primer dan data sekunder. Tika (1997: 67) mendeskripsikan Data primer adalah data yang diperoleh langsung dari responden atau obyek yang diteliti, atau ada hubungannya dengan yang diteliti. Data sekunder adalah data yang lebih dahulu dikumpulkan dan dilaporkan oleh orang atau instansi di luar diri peneliti sendiri, walaupun yang dikumpulkan itu sesungguhnya adalah data yang asli”.

Dalam penelitian ini data primer yang diperoleh adalah lokasi absolute yang ditunjukkan dengan lintang dan bujur dari masing - masing SD yang ada di daerah penelitian. Penggunaan data sekunder dalam penelitian ini adalah data dari Peta Rupabumi Indonesisa (RBI) yang digunakan sebagai base map atau peta dasar, serta jumlah ruang kelas dan siswa usia sekolah dasar yang ada di daerah penelitian.

Teknik pengumpulan data yang digunakan adalah : 1) Teknik Observasi. Teknik observasi dalam pengumpulan data merpakan teknik yang mengnakan semua indera untuk mencatat secara sistematik terhadap semua fenomena serta kejadian yang ada dilapangan. Dalam penelitian ini, teknik observasi digunakan untuk memperoleh data primer berupa data lokasi absolute sekolah dasar sebagai objek penelitian dengan menggunakan alat bantu berupa Global Positioning System (GPS). 2) Teknik 
Dokumentasi. Suharsumi Arikunto (2001:201)

"Teknik dokumentasi dilakukan dengan cara mengutip atau mengambil data dari sumber data yang telah tersedia." Teknik dokumentasi digunakan pada penelitian ini untuk mengutip data sekunder berupa layer peta dasar yang dikutip dari peta rupabumi Indonesia (RBI), selain itu digunakan untuk mengetahui jumlah siswa usia 7-13 tahun yang merupakan usia sekolah serta jumlah ruang kelas masing-masing sekolah. 3) Teknik Wawancara. Wawancara adalah teknik pengumpulan data yang digunakan peneliti untuk mendapatkan keterangan keterangan lisan melalui bercakap-cakap dan berhadapan muka dengan orang yang dapat memberikan keterangan pada si peneliti (Mardalis, 2002: 64). Data yang diperoleh dari teknik wawancar adalah data tentang keadaan ruang sekolah.

Teknik analisis data yang dilakukan dalam penelitian ini adalah teknik analisis data sekunder dan teknik analisis peta. Teknik analisis data sekunder dilakukan dengan cara mentabulasi data ke dalam bentuk tabel dan grafik maupun peta, kemudian diuraikan dalam bentuk kalimat. Adapun data yang perlu dianalisis adalah : 1) Analisis Persebaran SD. Analisis persebaran SD digunakan untuk mengetahui persebaran secara keruangan lokasi SD/MI yang berada di Kecamatan Bulu dengan menggunakan analisis peta. 2) Perbandingan Anak usisa sekolah dengan jumlah ruang kelas SD. Untuk mengetahui perbandingan anak usia sekolah dengan jumlah ruang kelas SD yang berada di Kecamatan Bulu dilakukan dengan menggunakan rumus APM (Angka Partisipasi Murni) yang telah dimodifikasi berdasarkan Permendiknas No. 15 Tahun 2010 sebagai berikut :

Kecukupan Ruang Kelas $(X)=$
Jumlah Anak usia $7-12$ tahun $/ 32$
Jumlah ruang kelas

Setelah diketahui angka perbandingannya, maka angka indek tersebut dimasukkan pada klasifikasi tingkat kecukupan ruang kelas dengan rincian :

$\mathrm{X}=0$ maka jumlah ruang kelas sesuai dengan jumlah siswa usia sekolah dasar

$\mathrm{T}>1$ maka jumlah ruang kelas mengalami kekurangan

$\mathrm{T}<1$ maka jumlah ruang kelas mengalami kelebihan

\section{HASIL DAN PEMBAHASAN}

\section{Pemetaan Persebaran SD}

Tercatat ada 34 Sekolah Dasar yang ada di Kecamatan Bulu dengan 33 sekolah bersatus negeri dan 1 sekolah berstatus swasta. Adapun lokasi koordinat sekolah dapat dilihat pada tabel berikut.

Tabel 1. Lokasi Koordinat sekolah

\begin{tabular}{|c|c|c|c|c|}
\hline No & Nama Sekolah & Alamat & $\mathrm{X}$ & $\mathrm{Y}$ \\
\hline 1 & SDN Bulu 01 & Sepat, Bulu & 7,7625 & 110,8361 \\
\hline 2 & SDN Bulu 03 & Bulu & 7,7633 & 110,8306 \\
\hline 3 & SDN Bulu 04 & $\begin{array}{l}\text { Soronanggan, } \\
\text { Bulu }\end{array}$ & $\begin{array}{r}- \\
7,7667\end{array}$ & 110,8350 \\
\hline 4 & SDN Gentan 01 & Jetis, Gentan & 7,7808 & 110,8428 \\
\hline 5 & SDN Gentan 02 & Garotan, Gentan & 7,7825 & 110,8339 \\
\hline 6 & SDN Gentan 03 & $\begin{array}{l}\text { Lengkongsari, } \\
\text { Gentan }\end{array}$ & 7,7808 & 110,8428 \\
\hline 7 & SDN Tiyaran 01 & $\begin{array}{l}\text { Tambakrejo, } \\
\text { Tiyaran }\end{array}$ & 7,7733 & 110,8536 \\
\hline 8 & SDN Tiyaran 02 & $\begin{array}{l}\text { Brenggalan, } \\
\text { Tiyaran }\end{array}$ & $7,781 \overline{-}^{-}$ & 110,8547 \\
\hline 9 & SDN Tiyaran 03 & Tiyaran, Bulu & 7,7725 & 110,8469 \\
\hline 10 & SDN Kedungsono & $\begin{array}{l}\text { Barngkulon, } \\
\text { Kedungsono }\end{array}$ & 7,7911 & 110,8564 \\
\hline 11 & $\begin{array}{l}\text { SDN Kedungsono } \\
02\end{array}$ & $\begin{array}{l}\text { Susuhan, } \\
\text { Kedungsono }\end{array}$ & 7,7878 & 110,8544 \\
\hline 12 & $\begin{array}{l}\text { SDN Kedungsono } \\
03\end{array}$ & $\begin{array}{l}\text { Malangan, } \\
\text { Kedungsono }\end{array}$ & 7,8006 & 110,8558 \\
\hline
\end{tabular}




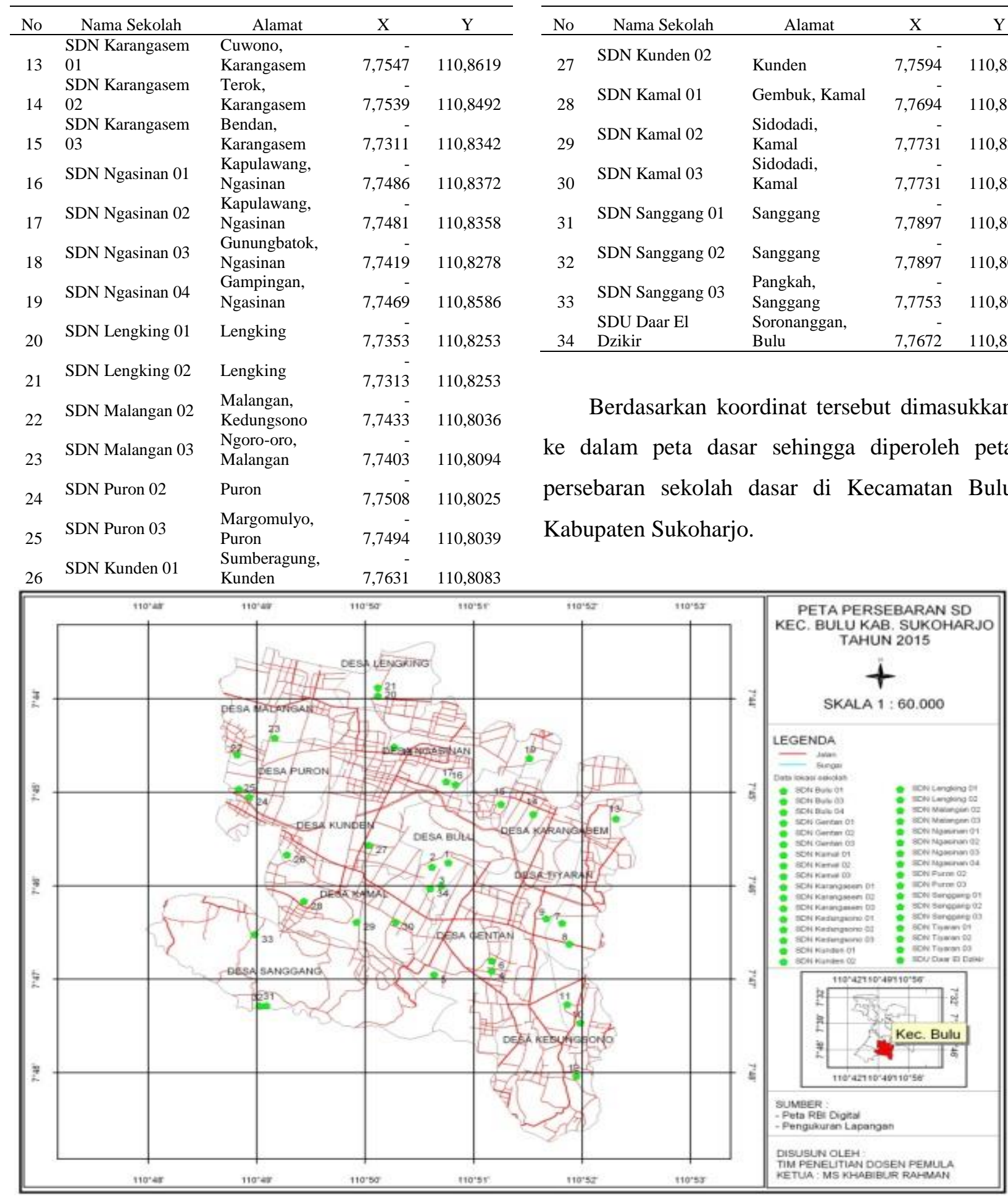

Gambar 1. Peta Persebaran Sekolah Dasar di Kecamatan Bulu

Penggambaran sekolah dilakukan dengan memberi simbol segi lima dengan warna hijau dan diberi keterangan angka, yang artinya masing-masing sekolah diwakili dengan satu simbol titik berbentuk segi lima tersebut.
Berdasarkan analisis distribusi peta di atas diketahui bahwa setiap desa di Kecamatan Bulu Kabupaten Sukoharjo memiliki sekolah dasar antara 2-4 sekolah, dengan desa yang paling banyak memiliki sekolah dasar adalah Desa Bulu 
dan Desa Ngasinan masing-masing 4 sekolah dasar.

Lokasi sekolah antara satu sekolah dengan yang lain relatif mempunyai jarak yang cukup jauh, namun ada beberapa sekolah yang lokasinya berdekatan bahkan memiliki halaman sekolah yang sama, yaitu SD negeri Lengking 1 dan 2 serta SD Negeri Sanggang 1 dan 2. Keberadaan sekolah yang letaknya bersebelahan akan memberikan dampak, baik dampak positif maupun dampak negatif. Dampak positif yang timbul adalah sekolah akan terlihat lebih ramai dengan siswa yang saling berbagi arena bermain, sedangkan dampak negatifnya secara tidak langsung akan menimbulkan persaingan antar sekolah.

\section{Kecukupan Ruang Kelas SD}

Permendiknas No. 15 Tahun 2010 telah mengatur bahwa setiap ruang kelas sekolah dasar maksimal dapat digunakan oleh 32 peserta didik, maka dari itu untuk mengetahui kecukupan ruang kelas di Kecamatan Bulu dilakukan dengan menggunakan rumus APM (Angka Partisipasi Murni) yang telah dimodifikasi berdasarkan Permendiknas No. 15 Tahun 2010 sebagai berikut :

\section{Kecukupan Ruang Kelas $(\mathrm{X})=$ Jumlah Anak usia 7-12 tahun//32 \\ Jumlah ruang kelas}

Setelah diketahui angka perbandingannya, maka angka indek tersebut dimasukkan pada klasifikasi tingkat kecukupan ruang kelas dengan rincian :

$\mathrm{X}=0$ maka jumlah ruang kelas sesuai dengan jumlah siswa usia sekolah dasar
$\mathrm{X}>1$ maka jumlah ruang kelas mengalami kekurangan

$\mathrm{X}<1$ maka jumlah ruang kelas mengalami kelebihan

Data anak usia 7-12 tahun diperoleh dari data Badan Pusat Statistik (BPS) yang merupakan lembaga resmi pencatat data kependudukan. Data yang diperoleh menunjukkan kelompok data usia dengan rentang jarak usia 5 tahun, sehingga kelompok umur tersebut dibagi menjadi 5 dengan asumsi setiap umur memiliki jumlah atau rasio yang sama.

Data yang diperoleh dari Badan Pusat statistik (BPS) Kabupaten Sukoharjo yang tertuang dalam buku Kecamatan Bulu dalm angka Tahun 2015 diketahui kelompok usia 5-9 tahun sebanyak 3.809 anak dengan rincian 1925 anak laki-laki dan 1884 anak perempuan. Kelompok usia 10-14 tahun memiliki jumlah anak 4647 anak dengan rincian 2263 anak lakilaki dan 2384 anak perempuan. Berdasarkan data tersebut, dipisahkan berdasarkan umur dengan membagi jumlah anak pada kelompok umur menjadi 5 kelompok dengan asumsi setiap kelompok mempunyai jumlah yang sama. Kelompok usia 5-9 tahun dengan jumlah anak 3809 dibagi 5 usia diperoleh angka 762 yang artinya anak usia 5 tahun berjumlah 762 , anak usia 6 tahun berjumlah 762, anak usia 7 tahun berjumlaj 762, anak usia 8 tahun berjumlah 762 dan anak usia 9 tahun berjumlah 762. Kelompok usia 10-14 tahun dengan jumlah anak 4647 orang, dibagi kedalam 5 usia diperoleh angka masing-maing usia 10 tahun sebanyak 929 anak, usia 11 tahun 929 anak, usia 12 tahun 929 anak, 
usia 13 tahun 929 anak dan usia 14 tahun 929 anak.

Anak usia sekolah dasar berusia antara 7-12 tahun, yang artinya jumlah anak usia sekolah dasar di Kecamatan Bulu berjumlah 5074 diperoleh dari penjumlahan anak usia 7-12 tahun. Sehingga dapat diketahui kecukupan ruang kelas di Kecamatan Bulu adalah sebagai berikut :

$$
\text { Kecukupan Ruang Kelas }(\mathrm{X})=\frac{5.074 \text { Anak/32 }}{213 \text { kelas }}
$$

$$
\begin{aligned}
& =\frac{158,55}{213} \\
& =0,744
\end{aligned}
$$

Setelah diketahui nilai kecukupan ruang sekolah dasar di Kecamatan Bulu lalu dikomparasikan dengan klasifikasi tingkat kecukupan ruang yang hasilnya adalah $\mathbf{X}<\mathbf{1}$ yang artinya jumlah ruang kelas mengalami kelebihan. Hasil perhitungan yang menunjukkan data kelebihan ruang kelas di Kecamatan Bulu Kabupaten Sukoharjo baru sebatas hitungan matematis saja, tentu perlu dikaji lebih mendalam mengenai kebutuhan ruang secara pasti. Perlu mempertimbangkan banyak aspek dalam menghitungnya, misalnya topografi dan aksesibilitas. Jika memang setelah dianalisis secara lebih mendalam, diketahui jumlah ruang kelas mengalami kelebihan tentu saja perlu dilakukan penggabungan sekolah guna efisiensi anggaran.

\section{DAFTAR PUSTAKA}

Arikunto, Suharsimi. (1996). Prosedur Penelitian. Jakarta : PT. Rineka Cipta.

Bintarto, R dan Hadisumarno, Surastopo. (1991). Metode Analisa Geografi. Jakarta : LP3ES.

Mardalis. (2002). Metode Penelitian. Jakarta : PT. Bumi Aksara.

Suryabrata, Sumadi. (2012) . Metodologi Penelitian. Jakarta : PT Raja Grafindo Persada

Tika, Moch Pabundu. (1997). Metode Penelitian Geografi. Jakarta : PT. Gramedia Pustaka Utama.

Villanueva, K.J. (1978). Kartografi. Bandung : Institut Teknologi Bandung

Yunus, Hadi Sabari. (2007). Subject Matter dan Metoda Penelitian Geografi Permukiman Kota. Yogyakarta : Fakultas Geografi Universitas Gadjah Mada.

Perundang-undangan :UU No. 20 Tahun 2003 tentang Sistem Pendidikan Nasional.

Permendiknas No.15 Tahun 2010

Internet : http://www.citizenjurnalism.com/worldnews/indonesia/sekolah-swasta-di-kota-serangterancam-tutup/ 